\title{
PERAN BADAN KEPEGAWAIAN DAN PENGEMBANGAN SUMBER DAYA MANUSIA KOTA METRO DALAM PENYELENGGARAAN DIKLAT PELATIHAN DASAR TAHUN 2019
}

\author{
Herman Sismono \\ Sekolah Tinggi Ilmu Sosial Dan Politik Dharma Wacana Metro \\ Email: hermansis19@gmail.com
}

\begin{abstract}
Increasing the quality of professionalism, an attitude of dedication and loyalty to the State and the development of insight into governance for Prospective Civil Servants to support the realization of good governance, namely through education and training guidance. Basic Training for 2019 Metro City Government Civil Servant Candidates was held by BKPSDM Metro City through the Human Resources Development Sector. The goal is to determine the role of the Metro City Personnel and Human Resources Development Agency for the implementation of the Class III CPNS Basic Training Class I Year 2019. With this research, it is hoped that the implementation of Basic Training Training can run better.

This study uses a qualitative method. The data sources used were primary and secondary data from interviews, observation and documentation. The data will be analyzed using descriptive analysis method. Based on the data analysis carried out, it was concluded that the Human Resources and Human Resources Development Agency of Metro City as the organizing committee has made every effort to smooth and successful the implementation of Basic Training Class III Class I Year 2019. This can be seen from the implementation of group dynamics activities to make participants become more comfortable during the Basic Training Training; providing modules and stationery to support learning activities during training; The provision of facilities and infrastructure is carried out in accordance with the budget constraints set by the Metro City Government; The determination of competent widyaiswara by submitting the results of the widyaiswara evaluation to the Lampung Province Education and Training Agency
\end{abstract}

Keywords: Training, Quality Improvement, Human Resources.

\begin{abstract}
ABSTRAK
Peningkatan mutu profesionalisme, sikap pengabdian dan kesetiaan pada Negara dan pengembangan wawasan tentang pemerintahan bagi Calon Pegawai Negeri Sipil untuk mendukung terwujudnya kepemerintahan yang baik yaitu melalui pembinaan pendidikan dan pelatihan. Pelatihan Dasar Calon Pegawai Negeri Sipil Pemerintah Kota Metro Tahun 2019 diselenggarakan oleh BKPSDM Kota Metro melalui Bidang Pengembangan Sumber Daya Manusia. Tujuannya untuk mengetahui peran Badan Kepegawaian dan Pengembangan Sumber Daya Manusia Kota Metro terhadap penyelenggaraan Pelatihan Dasar CPNS Golongan III angkatan I Tahun 2019. Dengan adanya penelitian ini diharapkan pelaksanaan Diklat Pelatihan Dasar dapat berjalan dengan lebih baik.

Penelitian ini menggunakan metode kualitatif. Adapun sumber data yang digunakan yang digunakan adalah datadta primer dan sekunder dari wawancara, observasi dan dokumentasi. Data akan dianalisa dengan metode deskriptif analisis. Berdasarkan Analisa data yang dilakukan, diperoleh kesimpulan bahwa Badan Kepegawaian Dan Pengembangan Sumber Daya Manusia Kota Metro selaku panitia penyelenggara telah berusaha semaksimal mungkin untuk kelancaran dan keberhasilan pelaksanaan Diklat Pelatihan Dasar Golongan III Angkatan I Tahun 2019.Hal ini terlihat dari dilaksanakannya kegiatan dinamika kelompok untuk membuat peserta menjadi lebih nyaman selama Diklat Pelatihan Dasar berlangsung; diberikannya modul dan alat tulis untuk menunjang kegiatan belajar selama diklat; Penyediaan sarana dan prasarana dilaksanakan sesuai dengan keterbatasan anggaran yang ditetapkan oleh Pemerintah Kota Metro; Penentuan widyaiswara yang berkompeten dengan cara menyampaikan hasil evaluasi widyaiswara ke Badan Diklat Propinsi Lampung
\end{abstract}

Kata Kunci: Pelatihan, Peningkatan Mutu, Sumber Daya Manusia. 


\section{A. PENDAHULUAN}

Peningkatan mutu profesionalisme, sikap pengabdian dan kesetiaan pada Negara dan pengembangan wawasan tentang pemerintahan bagi Calon Pegawai Negeri Sipil untuk mendukung terwujudnya kepemerintahan yang baik yaitu melalui pembinaan pendidikan dan pelatihan.

Pembinaan tersebut dilakukan melalui Pendidikan Dasar CPNS sebagaimana yang tertera dalam Undang- Undang Nomor 05 Tahun 2014 Tentang Aparatur Sipil Negara menyebutkan bahwa proses pendidikan dan pelatihan terintegrasi untuk membangun integritas moral, kejujuran, semangat dan motivasi nasionalisme dan kebangsaan, karakter kepribadian yang unggul dan bertanggung jawab, dan memperkuat profesionalisme serta kompetensi bidang.

Pelatihan Dasar CPNS Golongan III di lingkungan Pemerintah Kota Metro, Badan Kepegawaian dan Pengembangan Sumber Daya Manusia Kota Metro bekerjasama dengan Badan Pendidikan dan Pelatihan Daerah Propinsi Lampung dalam hal penentuan jadwal dan penentuan widyaiswara yang akan memberikan materi dalam pendidikan dan pelatihan tersebut.

Akan tetapi dalam pelaksanaannya terkadang ada juga peserta yang tidak mengikuti aturan yang ditetapkan selama mengikuti Pelatihan Dasar CPNS yang menyebabkan terjadinya ketidaklancaran penyelenggaraan Pelatihan Dasar CPNS.

1. Rumusan Masalah

Masalah dalam penelitian ini adalah "Bagaimanakah Peran Badan

Kepegawaian dan Pengembangan Sumber Daya Manusia Kota Metro terhadap keberhasilan penyelenggaraan Pelatihan Dasar CPNS Golongan III Pemerintah Kota Metro Tahun 2019"

2. Tujuan Penelitian

a) Untuk mengetahui peran Badan Kepegawaian dan Pengembangan Sumber Daya Manusia Kota Metro terhadap penyelenggaraan Pelatihan Dasar CPNS Golongan III angkatan I Tahun 2019.

b) Dengan adanya penelitian ini diharapkan pelaksanaan Diklat Pelatihan Dasar dapat berjalan dengan lebih baik ditahun-tahun yang akan datang.
3. Tinjauan Pustaka

Peran adalah perangkat tingkat yang diharapkan dimiliki oleh orang yang berkedudukan di masyarakat. Sedangkan Horton dan Hunt mengemukakan bahwa peran adalah perilaku yang di harapkan dari seseorang mempunyai status.

Peran Badan Kepegawaian dan Pengembangan Sumber Daya Kota Metro terhadap penyelenggaraan Pelatihan Dasar Golongan III angkatan I yaitu:

- Sebagai penyelenggara Pelatihan Dasar Golongan III Angkatan I

- Memberikan sarana dan prasana Pelatihan Dasar Golongan III Angkatan I

- Memberikan permohonan kepada Badan Pengembangan Sumber Daya Manusia (BPSDM) Provinsi Lampung dalam hal penentuan jadwal dan widyaiswara.

Berdasarkan Peraturan Walikota Metro Nomor 31 Tahun 2016 tentang Susunan, tugas dan Fungsi Perangkat Daerah Kota Metro, Badan Kepegawaian dan Pengembangan Sumber Daya Manusia Kota Metro mempunyai tugas pokok untuk menyelenggarakan sebagian kewenangan daerah di bidang manajemen kepegawaian, serta melaksanakan tugas lain yang sesuai dengan kebijakan yang telah ditetapkan oleh walikota berdasarkan Peraturan dan Perundang-undangan yang berlaku. Salah satu tugas yang ada di Badan Kepegawaian dan Pengembangan Sumber Manusia Daya Kota Metro adalah menyelenggarakan Pelatihan Dasar bagi para Calon Pegawai Negeri Sipil yang telah direkrut melalui pengadaan pegawai di Kota Metro serta mempunyai fungsi:

1) Perumusan kebijakan teknis dibidang pengadaan dan pemberhentian pegawai, mutasi dan pengembangan pegawai, pendidikan dan pelatihan pegawai, dokumentasi dan informasi kepegawaian;

2) Pemberian dukungan atas penyelenggaraan pemerintahan daerah dibidang pengadaan dan pemberhentian pegawai, mutasi dan pengembangan pegawai, pendidikan dan pelatihan pegawai, dokumentasi dan informasi kepegawaian;

3) Pembinaan dan pelaksanaan tugas dibidang pengadaan dan pemberhentian pegawai, mutasi, dan pengembangan 
pegawai, pendidikan dan pelatihan pegawai, dokumentasi dan informasi kepegawaian;

4) Penyelenggaraan kesekretariatan Badan;

5) Pelaksanaaan tugas lainyang diberikan oleh Walikota sesuai dengan tugas dan fungsinya;

Dalam Peraturan Pemerintah Republik Indonesia Nomor 101 Tahun 2000 Bab I pasal 1, pendidikan dan pelatihan adalah proses penyelenggaraan belajar mengajar dalam rangka meningkatkan kemampuan Pegawai Negeri Sipil.

Tujuan dari pendidikan dan pelatihan menurut Peraturan Pemerintah Republik Indonesia Nomor 101 Tahun 2000 yaitu:

1) Meningkatkan pengetahuan, keahlian, ketrampilan, dan sikap untuk dapat melaksanakan tugas jabatan secara profesional dengan dilandasi kepribadian dan etika PNS sesuai dengan kebutuhan instansi;

2) Menciptakan aparatur yang mampu berperan sebagai pembaharuan dan mempererat persatuan dan kesatuan bangsa;

3) Memantapkan sikap dan semangat pengabdian yang berorientasi pada pelayanan, pengayoman, dan pemberdayaan masyarakat;

4) Menciptakan kesamaan visi dan dinamika pola pikir dalam melaksanakan tugas pemerintahan dan pembangunan demi terwujudnya pemerintahan yang baik.

Manfaat Pendidikan dan Pelatihan menurut Wursanto (1989:60), ada berbagai manfaat pendidikan dan pelatihan pegawai, yaitu :

1) Pendidikan dan pelatihan meningkatkan stabilitas pegawai.

2) Pendidikan dan pelatihan dapat memperbaiki cara kerja pegawai.

3) Dengan pendidikan dan pelatihan pegawai dapat berkembang dengan cepat, efisien dan melaksanakan tugas dengan baik.

Dengan pendidikan dan pelatihan berarti pegawai diberi kesempatan untuk mengembangkan diri.

Kegiatan evaluasi merupakan suatu hal yang tidak dapat dipisahkan dari pendidikan dan pelatihan terutama dalam keseluruhan kegiatan belajar mengajar (Siswanto, 2003 :220). Berhasil atau tidaknya suatu program diklat tergantung pada hasil evaluasi yang dilakukan. Evaluasi sangat penting dilakukan karena implementasi program pendidikan dan pelatihan berfungsi sebagai proses transformasi, yaitu para pegawai yang terlatih diubah menjadi pegawai yang berkemampuan.

Dikemukakan oleh Dale yorder yang dikutip oleh Moh. Asad (1987), ada delapan faktor yang harus diperhatikan agar program Diklat dapat berhasil, yaitu: Individual differences; Relation to job analisis; Motivation; Active participation; Selection of trainess; Selection of trainer; Trainer training; Trainer methods.

\section{B. METODE PENELITIAN}

1. Jenis dan Pendekatan Penelitian

Jenis penelitian yang digunakan adalah penelitian kualitatif. Data-data yang dikumpulkan dalam penelitian kualitatif dapat berupa naskah, wawancara, rekaman, video, catatan di lapangan, dokumen pribadi ataupun memo.

2. Focus Penelitian

Fokus penelitian iniadalah sebagai berikut:

- Bagaimana penyelenggara Diklat Pendidikan Dasar Golongan III angkatan I dapat mengatasi kendala selama diklat berlangsung.

- Bagaimana tingkat kelulusan peserta diklat Pelatihan Dasar Golongan III angkatan I

- Apa saja sarana dan prasarana yang diberikan selama Diklat Pelatihan Dasar Golongan III Angkatan I

- Bagaimana Widyaiswara dalam penyampaian materi selama Diklat Pelatihan Dasar Golongan III Angkatan I

3. Lokasi Penelitian

Penelitian ini dilakukan di Badan Kepegawaian dan Pengembangan Sumber Daya Manusia Kota Metro, J1. A.H. Nasution No. 3 Kota Metro

4. Jenis dan Sumber data data primer dari penelitian ini yaitu peneliti melakukan wawancara dengan tim panitia penyelenggara Diklat Pelatihan Dasar. Sedangkan data sekunder dari 
E. ISSN : 2746-1629

penelitian ini yaitu didapat dari data-data Diklat, internet dan juga buku-buku.

5. Informan

Informan dalam penelitian ini adalah para pegawai di Bidang Pengembangan Sumber Daya Manusia pada Badan Kepegawaian dan Pengembangan Sumber Daya Manusia Kota Metro sebanyak 3 Orang karena sudah mewakili dari Tim Panitia Penyelenggara, Widyaiswara sebanyak 1 orang, dan peserta Diklat Pelatihan Dasar CPNS Golongan III angkatan I 3 Orang.

\section{Instrumen Penelitian}

Instrumen yang digunakan dalam penelitian ini yaitu; Wawancara (interview guide); Catatan Lapangan (field notes); Pedoman observasi (observation schedule); Alat tulis.

7. Proses dan Teknik Pengumpulan Data

Dalam penelitian ini pengumpulan data dilakukan melalui tiga tahapan yaitu: Proses memasuki lokasi penelitian; Ketika berada dilokasi penelitian; Mengumpulkan Data (wawancara mendalam; observasi; dokumentasi).

8. Keabsahan Data

Derajat Kepercayaan (credibility); Keteralihan (transferability); Ketergantungan (dependability) dan Kepastian (confirmability).

9. Teknik Analisa Data

Open coding, axial coding, dan selective coding.

\section{HASIL PENELITIAN DAN PEMBAHASAN}

1. Hasil Penelitian

a) Dalam hasil penelitian didapatkan bahwa penyelenggaraan Diklat Pelatihan Dasar Golongan III Angkatan I Tahun 2019 telah berusaha semaksimal mungkin untuk kelancaran pelaksanaan Diklat.Faktor yang mempengaruhi keberhasilan Diklat Pelatihan Dasar Golongan III Angkatan I Tahun 2019 yaitu : Individual differences; Relation to job analisis; Motivation; Active participation; Selection of trainess; Selection of trainer; Trainer training; Trainer Methods.

b) Kendala yang dihadapi oleh pihak penyelenggara sampai dengan penentuan tingkat kelulusan peserta. Hal tersebut terjadi karena keberagaman peserta yang mengikuti Diklat Pelatihan Dasar Golongan III Angkatan I Tahun 2019.

2. Pembahasan

Berdasarkan wawancara yang di lakukan didapatkan hasil sebagai berikut:

a) Selama kegiatan Diklat Pelatihan Dasar Golongan III Angkatan I Tahun 2019 panitia penyelenggara telah melakukan dinamika kelompok untuk menyatukan persepsi para peserta sehingga peserta dapat mengikuti Diklat Pelatihan Dasar Golongan III Angkatan I Tahun 2019 dengan nyaman.

b) Pada kegiatan Diklat Pelatihan Dasar Golongan III Angkatan I Tahun 2019 para peserta telah lulus dengan predikat baik, adapun kriteria penilaian meliputi : disiplin, kepemimpinan, kerjasama, aktualisasi di tempat kerja dan ujian tertulis

c) Pada Diklat Pelatihan Dasar Golongan III Angkatan I Tahun 2019 panitia telah memberikan modul, alat tulis kantor, seragam olah raga dan tanda peserta kepada peserta demi kelancaran pelaksanaan diklat.

d) Ada beberapa peserta Diklat Pelatihan Dasar Golongan III Angkatan I Tahun 2019 selama mengikuti diklat mempunyai perasaan terpaksa, akan tetapi semua ini dapat dikendalikan dan tidak mempengaruhi kegiatan Diklat Pelatihan Dasar Golongan III Angkatan I Tahun 2019.

e) Widyaiswara dituntut untuk mempunyai kompetensi dan menguasai kurikulum yang diajarkan kepada para peserta. Dalam kegiatan Diklat Pelatihan Dasar Golongan III Angkatan I Tahun 2019 ada widyaiswara yang dalam menyampaikan materi menyimpang dari kurikulum. Akan tetapi panitia telah menyampaikan hasil evaluasi terhadap widyaiswara ke Badan Diklat Daerah Propinsi Lampung sehingga untuk yang akan datang widyaiswara tersebut dapat lebih mampu menguasai materi.

f) Kegiatan Diklat dapat berjalan dengan baik apabila didukung sarana dan 
prasarana yang baik juga. Pada Diklat Pelatihan Dasar Golongan III angatan I Tahun 2019, panitia penyelenggara telah memberikan sarana dan praasarna sesuai dengan standar pada anggaran kegiatan Diklat Pelatihan Dasar Golongan III angatan I Tahun 2019.

g) Menurut informan yang berinisial TY, selaku widyaiswara telah menyampaikan materi sesuai dengan kurikulum. Widyaiwara memberikan materi juga penerapan-penerapan yang ditungkan dalam tugas-tugas perorngan maupun tugas kelompok. Selain itu widyaiswar juga haru mempunyai kiatkiat khususnya agar kegiatan belajar menjadi menyenangkan.

h) Dari hasil wawancara dengan TY, maka selaku widyaiswara berharap agar pelaksanaan yang akan datang menjadi lebih baik lagi dan kepada peserta diharapkan dapat menerapkan ilmu-ilmu yang didapat selama Diklat Pelatihan Dasar.

\section{KESIMPULAN DAN SARAN}

1. Kesimpulan

Badan Kepegawaian Dan Pengembangan Sumber Daya Manusia Kota Metro selaku panitia penyelenggara telah berusaha semaksimal mungkin untuk kelancaran dan keberhasilan pelaksanaan Diklat Pelatihan Dasar Golongan III Angkatan I Tahun 2019.

2. Saran

a. Adanya dukungan sarana dan prasarana yang memadai yang menjadi faktor penunjang keberhasilan Diklat Pelatihan Dasar Golongan III Angkatan I Tahun 2019 untuk yang akan datang agar ditingkatkan lagi.

b. Dalam penyelenggaraan dana selayaknya disesuaikan dengan hasil yang akan diterima, misalnya dalam penyiapan sarana dan prasarana sehingga dapat lebih optimal lagi penyediaannya. Sehingga peserta merasa lebih nyaman selama kegiatan diklat berlangsung. c. Penentuan widyaiswara sebaiknya yang berkompeten sehingga dapat memberikan materi sesuai dengan kurikulum.

d. Kedisiplinan peserta sebaiknya lebih ditertibkan, sehingga peserta dapat mengikuti diklat sesuai dengan aturan.

e. Kepada Panitia penyelenggara yaitu di Badan Kepegawaian Dan Pengembangan Sumber Daya Manusia Kota Metro saat ini hendaknya dapat lebih meningkatkan kemampuannya dalam memberikan pelayanan dan pelaksanaan Diklat Pelatihan Dasar Golongan III Angkatan I Tahun 2019 sehingga penyelenggaraan Diklat Pelatihan Dasar Golongan III kedepannya dapat berjalan lebih baik lagi.

\section{DAFTAR PUSTAKA}

Anselm L. Strauss dan Juliet Corbin. 1990. Basic of Qualitative Research: Grounded Theory, Procedures and Technique Sage Publication, Inc,

Arikunto.2006. Prosedur Penelitian Suatu Pendekatan Praktik. Yogyakarta : Rineka Cipta

Bachri Bachtiar S.2010. Meyakinkan validitas data melalui Triagulasi Pada Penelitian Kualitatif. Universitas Negeri Surabaya. Surabaya.

Depdikbud. 1993. Kamus Besar Bahasa Indonesia . Jakarta : Balai Pustaka

Nasution, Prop. Dr, S. 2003. Manajemen Penelitian Naturalistik Kualitatif. Tarsito. Bandung

Peraturan Lembaga Administrasi Negara Nomor 12 Tahun 2018 Tentang Pedoman Penyelenggaraan Pelatihan Dasar CPNS.

Peraturan Pemerintah RI Nomor 101 Tahun 2000 Tentang Pendidikan Dan Pelatihan Jabatan Pegawai Neger Sipil.

Peraturan Pemerintah RI Nomor 11 Tahun 2017 Tentang Manajemen Pegawai Neger Sipil. 
P. ISSN: $2540-816 \mathrm{X}$

E. ISSN : 2746-1629

Peraturan Walikota Metro Nomor 31 Tahun 2016 Tentang Susunan, Tugas dan Fungsi Perangkat Daerah Kota Metro.

UndangUndang Nomor 5 Tahun 2014 Tentang Aparatur Sipil Negara.

Yenrizal. Membuat Rumusan Masalah Dan Tujuan Penelitian. Http://Www.Trijayafmplg.Co.Id/2012 /12/Kuliah-With-Dosen-MembuatRumusan-Masalah-Tujuan-

Penelitian/ 